\title{
Teacher as envolver: a new role to play in English language discussion classes
}

\author{
Reza Pishghadam ${ }^{1}$, Masoud Mahmoodzadeh${ }^{2}$, Elham Naji Meidani ${ }^{1}$ and Shaghayegh Shayesteh ${ }^{*}$ \\ ${ }^{1}$ Ferdowsi University of Mashhad, Iran. \\ ${ }^{2}$ Language Department, Institute for the Intellectual Development of Children and Young Adults, Mashhad, Iran.
}

\begin{abstract}
Given the role of emotional factors in effective teaching and inspired by a number of socio-philosophical, linguistic and psychological theories including Developmental, Individual-difference, Relationship-based (DIR) model and the concept of emotioncy, the present study is an attempt to introduce envolver as a new role for teachers. Sense-related emotions towards a word or an entity that can relativise cognition fluctuate from avolvement (having no feelings) and exvolvement (having heard, seen or touched) to involvement (having had direct experience or having done research). Accordingly, teachers seem to adopt an envolving role in which they avolve, exvolve or involve the learners in different classroom practices. By conducting semi-structured interviews, the researchers asked 24 language teachers to nominate the topics they preferred the learners to be avolved, exvolved or involved in class. The findings revealed thematised topics for each category, including taboos for avolvement, routine topics for exvolvement, and life-related and thought-provoking ones for involvement. Finally, the results were discussed in the context of education.
\end{abstract}

Keywords: Teacher roles, education, emotioncy, envolver, language teacher.

\section{INTRODUCTION}

Teacher success or effectiveness has often been subjected to numerous educational variables; however, generally a successful teacher is clearly a person whose skills and attempts enhance academic achievements in an optimal manner (Parsley \& Corcoran, 2003). In reality, a recurring question in the past debates on pedagogical studies in teacher education has addressed the roles ascribed to the teacher in the classroom. In this sense, one of the central issues underlying the past debates about teacher roles has been concerned with the knowledge and skills that different approaches demand of teachers to be successful in the teaching profession. As such, the extensive writing on teacher roles in education may suggest that teachers deal with the pre-determined goals to reach, the tasks to perform and the specific teaching practices and actions to undertake in order to impart knowledge to students efficiently (Mir \& Jain, 2016). By and large, these roles are determined by a variety of approaches rooted in major schools of thought in philosophy, psychology, sociology, neurology, etc. The major teacher roles can be classified into behavioristic, cognitive, humanistic, constructivist and emotional ones, the last of which has recently received burgeoning attention (e.g., Goleman, 1995; Greenspan, 1992; Greenspan \& Shanker, 2004; Greenspan \& Wieder, 1998; Salovey \& Mayer, 1990; Tormey, 2005).

Following a number of innovations in psychology of emotions, from the introduction of 'emotional intelligence' (Salovey \& Mayer, 1990) to introducing Developmental Individual-difference Relationship-based (DIR) model (Greenspan, 1992) and 'emotioncy' (Pishghadam, Tabatabaeyan et al., 2013; Pishghadam, 2015; Pishghadam, Baghaei et al., 2016), teachers are required to take on different emotional roles in the classroom (Pishghadam, Adamson et al., 2013). In this regard, emotioncy as a

"Corresponding author (shaghayegh.shayesteh@gmail.com; (iD https://orcid.org/0000-0002-2375-285X) 
new psychological concept seems to have the potential to define new roles for teachers. Emotioncy has been characterised as sense-related emotions which can relativise cognition, ranging from avolvement (null) and exvolvement (auditory, visual, kinesthetic) to involvement (inner and arch) (Pishghadam, 2015). From this perspective, teachers seem to assume an 'envolving' role in which they avolve, exvolve, or involve the learners based on the classroom situations. In fact, depending on the topics they are facing in the class, they decide on the kinds of emotioncy (null, auditory, visual, kinesthetic, inner, and arch) which should be reinforced to teach more effectively. This intellectual development can be done through didactic practices which engage more senses.

Overall, considering the undeniable role of emotional factors in effective teaching (Pishghadam, Adamson et al., 2013; Pishghadam, Tabatabaeyan et al., 2013; Swain, 2013) and Pishghadam, Adamson et al.'s (2013) ideas on the novel dimension of emotions as a byproduct of sensory experiences (i.e., emotioncy), this study intends to introduce 'envolver' as a new teacher role (see Figure
1), which can first help teachers themselves to survive in an educational setting, and second, to deliver more effective education.

With that in mind, in this study the researchers used qualitative analyses to delineate the newly proposed concept of envolver and to shed more light on the new roles teachers may take on to affect the learning trajectory.

\section{THEORETICAL BACKGROUND}

\section{Teacher roles}

At first glance, a brief review of the previous research on teacher education clearly points to the multiple and varied roles of the teacher proposed and developed through different approaches over the years. Given the definition and perception of teacher roles widely theorised to date, the researchers shortly focus on four schools of thought in educational psychology to give a full picture of the issue. The schools of thought reviewed

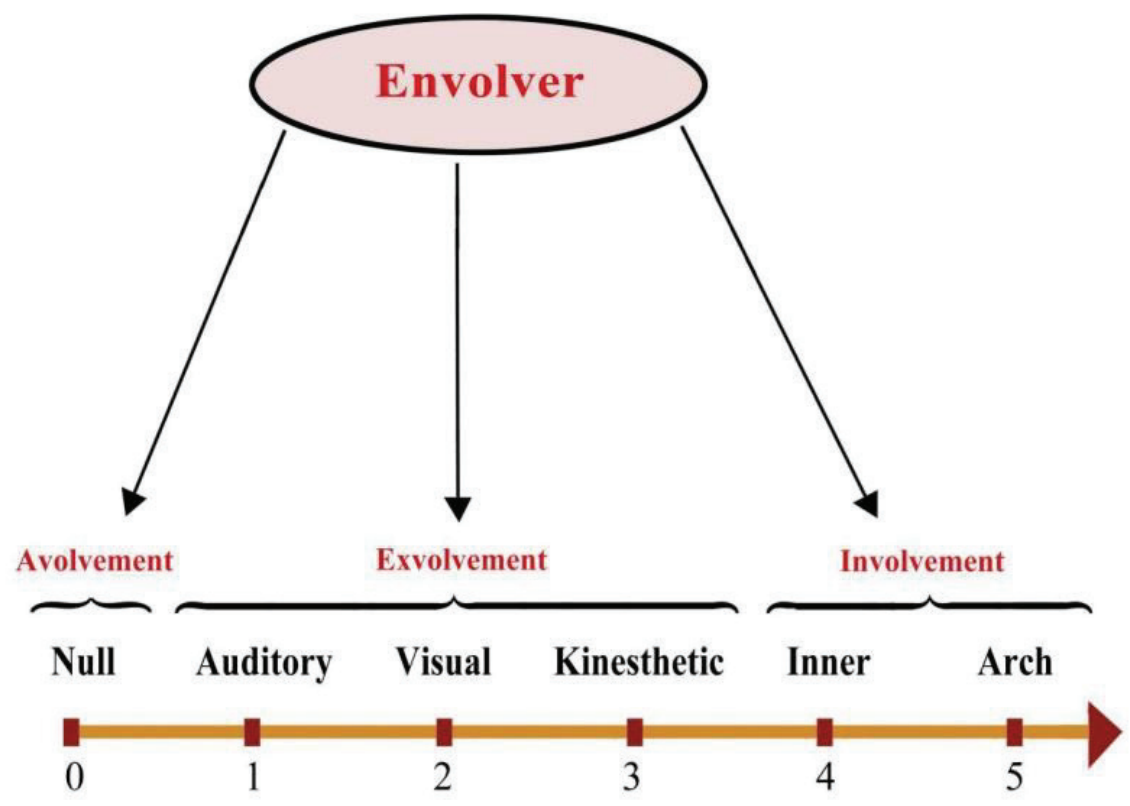

Figure 1: Envolver as a new teacher role laid on the emotioncy continuum 
in terms of teacher roles include behavioristic, cognitive, humanistic and constructivism approaches.

Throughout the history of educational psychology, theorising on the behaviorist view with its roots within positivism began to emerge in educational psychology during the first half of the twentieth century (Williams \& Burden, 1997). For many years, very many teachers and practitioners were concerned with only observable behaviors in the learning and teaching process in the classroom. While teachers play an active role in the learning process from the methodological point of view, learners are simply seen as the passive recipients of knowledge (Skinner, 1974). Learning is virtually envisaged as a pure stimulus-reaction mechanism achieved through conditioning, in which each behavior is learned as a habit using an appropriate kind of teachers' reinforcement (Ertmer \& Newby, 2013). Moreover, the roles assigned to the teachers clearly follow a scientific pedagogy/method as the orthodoxy in behaviorism, including a set of pre-determined steps to take for learning to take place; therefore, the teacher seems to act as an engineer, a leader and a role model for learners (Jones \& Brader-Araje, 2002).

In the 1950s, however, the educational approach to psychology was thoroughly changed by the advent of cognitive psychology; this cognitive view explores concepts, including perception, memory, attention, language and thinking/decision making (Brown, 2006). In contrast to behavioristic psychology, cognitive psychology is directly concerned with the human mind rather than external human behavior and highlights all the cognitive processes involved in information processing, in which case learners are seen as active participants in education (Ausubel, 1968). In terms of teacher roles, the teacher thus acts not only as an information provider and expert on the content knowledge, but also as a tutor and monitor who promotes and monitors a sense of problem solving or discovery in learners (Ausubel et al., 1978).

As for the humanistic approach in the mid-twentieth century, education was viewed as "involving the whole person, the emotions, and feelings; it does not involve transmitting pieces of knowledge" (Williams \& Burden, 1997: p. 33). In such an approach, Roger (1969) argues that learning is mainly self-initiated and takes place as both feelings and cognition are involved. In fact, educational psychology virtually witnessed a major shift of focus following Rogers's (1983) 'student-centered teaching', also known as 'experiential learning', as opposed to teacher-centered approaches and practices (Jones, 2007; Rogers \& Freiberg, 1994). Along with this movement, focus of attention shifted from 'teaching' towards 'learning' which requires specific skills, roles, and personal attitudes on the side of the instructor to see his learners as clients, enhances their personal security and takes over the role of facilitators as such (Roger, 1983). In addition, the teacher roles considered in this approach aim at increasing individual happiness, wellbeing and satisfaction to facilitate the learning process (Claman et al., 2014).

The next approach examined in this paper relates to constructivism, which was developed in the late twentieth century. In constructivism, learning is viewed as an active knowledge construction process (Fosnot, 1996; Spivey, 1997), where the concept of 'onesize-fits-all' methodology with absolutely clear-cut educational objectives are also entirely rejected and avoided (Motschnig-Pitrik \& Holzinger, 2002). In the late twentieth century, however, two of the most known theorists theorising on the constructivist paradigm in developmental and social psychology were Jean Piaget and Lev Vygotsky, who have significantly enriched the literature so far (e.g., Piaget, 1962; Vygotsky, 1978; 1986). Yet, interestingly enough, these two constructivists hold different views; each emphasising different aspects of constructivism (Blake \& Pope, 2008).

As discussed by Mir \& Jain (2016), Piaget believes that the process of knowledge construction is completely individual and that individuals construct knowledge based on their own prior knowledge through adaptation, whereas Vygotsky stresses the key role of the group and social interaction in initiating the construction of knowledge in individuals. According to Piaget (1962), the teacher seems to take on the role of a guide, coach or collaborator who helps learners in and of themselves to acquire knowledge. On the other hand, drawing upon Vygotskian perspectives, the teacher seems to take a mediating role in education rather than a central and/or peripheral role (Wiliams \& Burden, 1997).

Along with the development of teaching methods, feelings and emotions, individual perspectives and more generally, life-pertinent issues gradually mingled with the underlying techniques and strategies, make the traditionally limited roles of teachers more complex. In order to redefine the role of teachers and account for its multidimensionality, the researchers have come up with the new idea of envolver, valuing the unexplored influence of learners' sense-related, emotional experiences. Looking back at the approaches discussed earlier, in fact, it seems that the enterprise of describing the psychological roles of the teacher in education has often been increasingly highlighted as more approaches to educational psychology have gradually emerged in the literature over the years. In this sense, arguably, there still seems to be an urgent need for reopening the agenda of 
emotions in education in order to be able to shed further light on the teacher roles. In psychological discussions of education, however, language education seems to be an important discipline, having immediate emotional bearing upon thought and practice in education, which has frequently given directions to thinking on the teacher roles. Thus, given the significance of language in education, the study attempts to particularly focus on language education to come up with a full picture of education in light of the teacher roles. In some respects, one of the recent emotional perspectives addressing effective learning and teaching in language education over the recent years is related to a concept called 'emotioncy' (Pishghadam, Adamson et al., 2013; Pishghadam, Tabatabaeyan et al., 2013), which is briefly explained below.

\section{Emotioncy}

Prioritising the missing role of emotions in teaching and learning, Pishghadam, Adamson et al. (2013) breathed a new life into the field of second language education by introducing the Emotion-Based Language Instruction (EBLI). The EBLI hinges on the sensory emotions learners bring into play from their first language (L1) experiences and is structurally explicated under three complementary concepts of emotioncy, emotionalisation and inter-emotionality (Pishghadam, Adamson et al., 2013).

Emotioncy, as the core concept of this approach, is mainly derived from a juxtaposition of a number of sociophilosophical, linguistic and psychological concepts. From the socio-philosophical point of view, emotioncy is rooted in Alfred Schutz's phenomenology of the life-world experience (Yu, 2005) and also the theories of embodiment (e.g., embodied cognition, extended cognition, situated cognition, etc.), which accentuate the formative role of environment and the sensorimotor capabilities of the body beyond the mind in the development of cognition (Atkinson, 2010). Extending the concept to the learning domain, Vygotsky (1978) argues the way action experience affects the agent's perception of the world. Looking from the cognitive linguistics lenses, emotioncy is similarly embedded in Lakoff \& Johnson's (1999) general theory of embodied mind, based on which comprehension is shaped up by reference to sensorimotor system and emotions. Psychologically speaking, the underlying premises of emotioncy lie in the DIR model of Greenspan (1992) which integrates affect into the individual's intellectual faculty and thus, emphasises the key role of emotions and supportive relationships in improving the learning process in education (Greenspan, 1992).

As for the psychological concept of emotioncy, it refers to the varying degrees of sensory emotions that each entity (either a word or a concept) evokes and carries for each individual, depending on whether they have heard about, seen, touched or experienced that entity in their own context (Pishghadam, Adamson et al., 2013) (Table 1). According to the modality experiences, emotioncy is put down to different types and kinds.

To clarify, Pishghadam, Adamson et al. (2013) exemplify that a child has stronger emotions for the word "banana" because he has seen, smelled, touched and tasted the fruit, whereas he has weaker emotions for the words "knife", "cook" and "chopsticks", respectively, due to limited or lack of sensory involvement, hence modality representation in the brain (Binder, 2016). In addition, Pishghadam (2015) put the concept of emotioncy on a six-level emotioncy matrix (see Figure 2), ranging from avolvement (null) to exvolvement (indirect involvement resulting from Auditory, Visual and Kinesthetic emotioncies) and involvement (full internalisation of a concept through direct involvement, i.e., Inner and Arch emotioncies) as illustrated in Figure2.

In his recent article, Pishghadam (2016) statistically extended the previous metric to better capture learners'

Table 1: Emotioncy types and kinds.

\begin{tabular}{|c|c|c|}
\hline Emotioncy types & Emotioncy kinds & Experience \\
\hline Avolvement & Null emotioncy & $\begin{array}{l}\text { When an individual has not heard about, seen, or experienced an } \\
\text { object or a concept }\end{array}$ \\
\hline \multirow{3}{*}{ Exvolvement } & Auditory emotioncy & When an individual has merely heard about a word/concept \\
\hline & Visual emotioncy & When an individual has both heard about and seen the item \\
\hline & Kinesthetic emotioncy & $\begin{array}{l}\text { When an individual has touched, worked, or played with the real } \\
\text { object }\end{array}$ \\
\hline \multirow{2}{*}{ Involvement } & Inner emotioncy & When an individual has directly experienced the word/concept \\
\hline & Arch emotioncy & When an individual has done research to get additional information \\
\hline
\end{tabular}

(Adapted from- Pishghadam, R., Jajarmi, H., \& Shayesteh, S. (2016) Conceptualizing sensory relativism in light of emotioncy: A movement beyond linguistic relativism, International Journal of Society, Culture \& Language, 4(2), p. 16. Copyright 2016 by the IJSCL. Reprinted with permission.) 
level of emotioncy (Figure 3). The metric is a combination of Frequency (the amount of exposure to a particular type of sense) and Emotion (the valence of emotions for the specific object) measures. While Frequency ranges from 'a little' to 'a lot', Emotion varies from negative to neutral and positive.

In their study following the advent of emotioncy in education, through a qualitative piece, Pishghadam, Jajarmi et al. (2016) introduced 'Sensory Relativism' as a new complementary view beyond linguistic relativism (Whorf, 1956) through which sensory experiences are emphasised to shape up cognition. In accordance, they maintain that one's senses can relativise one's understandings of the world as such. Taking the crux of emotioncy argument into account, it seems that, grounded in miscellaneous full-fledged theories, emotioncy is equally bolstered by the idea of sensory constructivism, arguing that individuals can construct their idiosyncratic perceptions of the world through their own modalities (Pishghadam, Jajarmi et al., 2016).

Thus, with emotioncy moving towards emotionalising the instructional practices in education, the present paper aims to view the teacher roles in language education in light of emotioncy to see when and how teachers decide to avolve, exvolve and involve their learners in the classroom context.

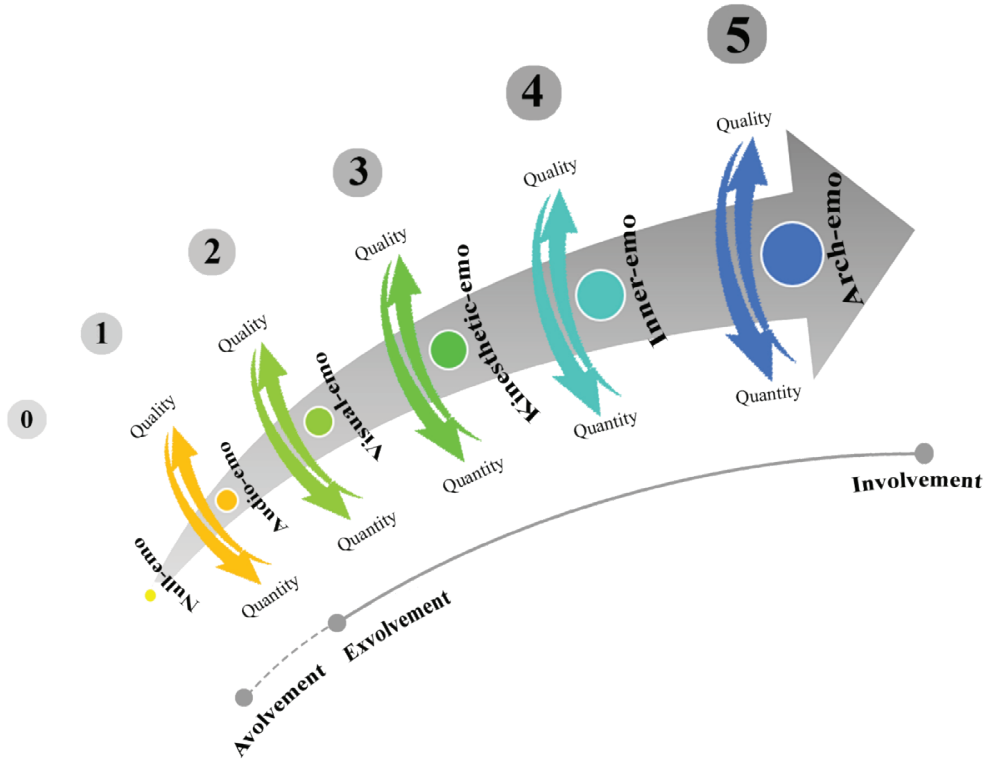

Figure 2: Emotioncy levels

(Adapted from- Pishghadam, R. (2015, October) Emotioncy in language education: From exvolvement to involvement, The $2^{\text {nd }}$ conference on Interdisciplinary Approaches on Language Teaching, Literature, and Translation Studies, Iran, Mashhad).

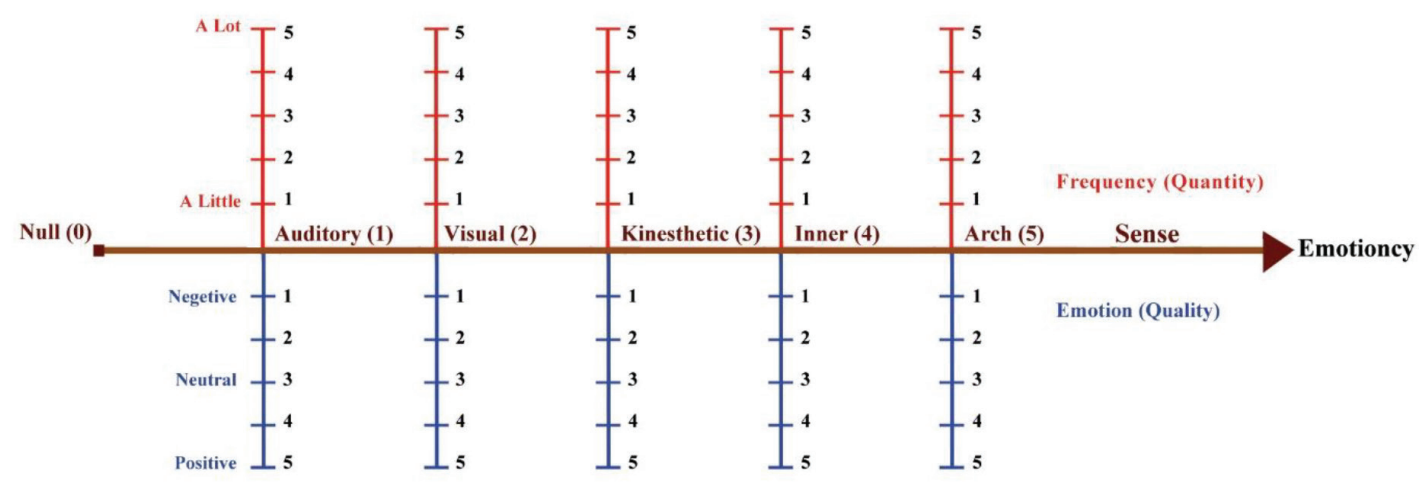

Figure 3: A metric for measuring emotioncy

(Adapted from- Pishghadam, R. (2016, May) Emotioncy, extraversion, and anxiety in willingness to communicate in English, The $5^{\text {th }}$ International Conference on Language, Education, and Innovation, pp. 1-5, UK: Infobase Creation Sdn Bhd.) 


\section{METHODOLOGY}

In carrying out the study, the researchers used a qualitative research method to collect the necessary data for analysis and discussion. To do so, the qualitative data was obtained through interviews as the preferred mode of data gathering in this study. The criteria used for selecting and using interview as the instrument of the study were to meet the goals of the study. Use of qualitative data to conduct studies has been recommended and highlighted in education by many researchers (e.g., Bogdan \& Biklen, 1997; Merriam, 1998; Patton, 2002; Silverman, 2013). In particular, however, using interviews to collect data in qualitatively-oriented studies is quite a well-established qualitative method of enquiry in itself (Dörnyei, 2007; Rubin \& Rubin, 2006).

\section{Participants and context}

This study was conducted on 24 Iranian language teachers [ 16 females and 8 males, within the age range of 21 to 41 (mean $=29)$ ], who taught English as a foreign language (TEFL) in 6 private language schools in Mashhad, a city in the eastern part of Iran. A major logic behind selecting the sample was that each school was located in a different region of the city. Moreover, those schools were singled out which offered free discussion courses and were popular enough to recruit more qualified teachers. The participants' native language was Persian and they had 5 to 15 (mean $=9$ ) years of language teaching experience. The teachers had all majored in the various branches of English including, English teaching (TEFL) $(\mathrm{N}=13)$, English literature $(\mathrm{N}=5)$, English translation $(\mathrm{N}=4)$ and linguistics $(\mathrm{N}=2)$ at $\mathrm{BA}(\mathrm{N}=7)$, $\mathrm{MA}(\mathrm{N}=13)$ or $\mathrm{PhD}(\mathrm{N}=4)$ levels. It is worth mentioning that, within the Iranian context, individuals majored in different branches of English are permitted to teach and that English is mostly taught at private language schools for communicative purposes. Relying on the Islamic culture of the country, the coursebooks used in this context are often censored to conform to religious norms and values. Teachers should likewise run the class taking multiple limitations into account. Thus, the appropriate topics which allow for classroom discussions in Iran may be quite different compared to those taken up by teachers from different parts of the world.

\section{Procedure}

The sampling procedure was purposive and the data was collected until the saturation criterion was met. The reason the study selected English language teachers was that, in English language classes teachers are supposed to freely discuss a wide range of topics in English. To gather the data, a semi-structured interview was conducted within 20 minutes. The questions were designed based on the definitions of avolvement, exvolvement and involvement provided by Pishghadam (2015). The participants, first were briefed on the meanings of these terms and second were asked to answer the following questions:

1. What topics do you prefer to avolve the students of (i.e., avoid) in class? Why?

2. What topics do you prefer to exvolve the students in (i.e., teach verbally, use pictures, etc.), in class? Why?

3. What topics do you prefer to involve the students in, in class? Why?

\section{RESULTS}

Subsequent to collecting the required data through the interview, the results were carefully examined to be thematised according to the given responses. The themes extracted from the teachers' responses were categorised into three groups with avolved, exvolved and involved topics depending on the given interview questions. The obtained findings are summarised in Table 2.

As shown in Table 2, the participants mentioned different themes for each type of topic. In this section, the themes for each topic are elaborated on, based on what the participants expressed.

Table 2: Thematised topics extracted from the teachers' responses to the interview questions

\begin{tabular}{ll}
\hline Type of topics & Themes \\
\hline Avolved & Taboos (drinking alcohol \& sex), religion and politics \\
Exvolved & Routine topics, book-related topics, gender-based topics and life irrelevant topics \\
Involved & $\begin{array}{l}\text { Job-related topics, life-related topics, thought-provoking topics, complicated topics and future } \\
\text { related topics }\end{array}$ \\
\hline
\end{tabular}




\section{Avolved topics}

These topics were the ones that the teachers avoided in class and kept the students away from making any emotional connection with. Grounded in the Islamic ambience of Iran, most of the topics were taboo, offlimits or unmentionable such as drinking alcohol or sex. Since drinking alcohol is "illegal in Iran", some teachers preferred not to discuss it in class, while some others took into account the age of the students or their gender; "It depends on whether the class is a mixed one or not. In mixed classes I prefer to avoid the topic not to spotlight the gender-based drinking gap". There was also a fear of students reporting to authorities and "having a bad effect on their career", which is the consequence of breaking the norms. The same was true for sex. The teachers mentioned that, "it depends on the students' age to discuss it" and that "Iranian students, especially girls, are shy to discuss it but boys prefer to talk about it". Therefore, again the two factors of students' age and gender were at play. Discussing sex in class had a further consequence for teachers. They were of the belief that it would result in "students not taking the class seriously any more". Overall, it was perceived "as taboo and not common to talk about in public".

Two other general topics that were silenced by teachers were religion and politics. Since these are considered as sensitive topics in Iran, contextual and environmental reasons lie behind their avolvement. The teachers believed that talking about religion in class might cause "tension" or bring about "misunderstanding". Moreover, "since students come from different religions, they may insult each other" or some students "have low tolerance" towards different or opposing religious beliefs. On the other hand, some teachers were of the opinion that "it may hurt some students' feelings by excluding them". There were also teachers who did not like to bring up the topic due to their own "lack of comprehensive knowledge" about it. Similar reasons were raised for the avoidance of politics: "Political issues are thorny topics in Iran and may cause us a lot of problems and some students may misunderstand us" and "politics is dangerous". The contextual nature of the topic gave rise to "fear of losing their job". Some of the teachers were not in favor of the topic because they regarded it as personal and were not willing to "betray their political ideas" in general or simply just "hated politics".

\section{Exvolved topics}

As already mentioned, exvolvement means having auditory, visual or kinesthetic emotioncy for something.
Therefore, exvolved topics are the ones that teachers teach verbally, use visual presentations or have the students touch a related entity or act out a related concept. The topics that the teachers mentioned for this category were mostly routine or book-related ones. Some teachers regarded routine topics as "unimportant" and having "no need for clarification". Therefore, they used "the auditory style of teaching" or "auditory inputs" to save the class time. It seems that they also considered these topics as mundane and dull and thus, "used videos to make them fun".

For book-related topics, the teachers taught "based on the students' styles of learning (auditory, visual, and kinesthetic)". The teachers did their best to have the students understand the material. One of the teachers stated, "I use pictures for clarification and understanding" (visual emotioncy). Another one mentioned following the guidelines proposed in the textbook; "so when the book says to use videos I do the same" (auditory and visual emotioncies). Moreover, some teachers tried to exvolve their students in gender-based or uninteresting topics often included in the coursebooks: "when my female students do not show interest in male-oriented topics like compulsory military service or soccer leagues and teams, I tend to provide them with auditory and visual explanations only". A lack of relevance to real life concepts was an additional reason which made teachers be exvolving rather than involving. A teacher believes that, "dealing with the complex names and details of the Milky Way, for instance, is way beyond my students' life-world experiences".

\section{Involved topics}

As discussed earlier, this category includes topics that entail inner emotioncy (when an individual has directly experienced the word/concept) and arch emotioncy (when an individual has done research into that concept to get additional information). In fact, more important, worthwhile and perhaps challenging topics fall into this category. Accordingly, thoughtprovoking and complicated topics were mentioned here. Thought-provoking topics are "more than copy and paste", therefore "students are engaged deeply in class discussions" and "they like to surf the net to come up with new ideas". Since students are completely involved, "they can really learn something from an English class". The teachers considered topics that "the books don't provide the necessary information on" as complicated. They believed that a "topic that is by itself very complicated and difficult; needs more digging". Thus, students do research to develop arch emotioncy for the topic. 
The teachers mentioned life-related topics as involved ones. They pointed out that "the class becomes real life when the students discuss life-related topics". Given that these topics include direct experience of concepts (inner emotioncy), "students show more interest in them" and "they become highly motivated to talk about them". This results in "students taking the class more seriously". The interviewees also drew on job-related topics to involve their students in. They mentioned that, "students are more interested in job-related topics" and "the class becomes more fruitful and students feel happy in class". Similarly, future-related topics were used to involve the students in. These topics were pertinent to the future in two senses: one, when they could be used "later in learning" and two, when they could be used "later in life and education".

\section{DISCUSSION}

The present study endeavored to reinvent the role of teachers according to the emotional aspects of learning and teaching, and more specifically, the concept of emotioncy. As an envolver, the teacher avolves, exvolves or involves the learners for different purposes. An envolver is expected to emotionalise (moving from avolvement to involvement) and Emotionalise (moving from avolvement to involvement) different things and concepts. The word emotionalisation refers to 'little e emotioncy', which is emotioncy at the individual level and the word Emotionalisation refers to 'big e emotioncy', which is related to emotioncy at the collective level. Following the tenets of the communicative approach broadly used in language classes today, one of the areas in which envolvement takes place is the topics used and discussed in the class. Due to their unique nature in cultivating distinct human abilities besides language learning, language classes allow for the discussion of various topics (Pishghadam, 2011). In particular, in English language classes, everyday life topics including society, culture, politics, etc. are discussed to provide the learners with new perspectives towards life issues (Pishghadam, 2011). Yet, not all the topics are equally favored by the teachers to exchange views on. Thereby, to illuminate, in this study a number of EFL teachers were asked what topics they preferred to avolve their students of or exvolve or involve them in.

As for the first research question which concerned avolvement, the participant teachers firstly mentioned taboos (e.g., drinking alcohol and sex) as topics they preferred to avoid in class. Of course, taboos, as the unavoidable element of every culture, vary across cultures and change as the societies change (Tekin, 2011). As stated by Evans et al. (2000), controversial issues receive little attention in class due to their challenging taboo nature. Although discussing the endless list of taboos can be quite motivating and involving, some students may not benefit and hence be offended or excluded (Banville, 2005). In a study done by Tekin (2011), interviews with EFL learners about their attitude towards taboo topics revealed that the main reason they avoided them was the risk of putting themselves in a critical position by using impolite words. They would even become embarrassed and avoid looking at the teacher's face directly while talking about such topics. Likewise, the results obtained in this study revealed that, given their own beliefs and backgrounds to preserve the cultural and social norms, teachers are also not willing to risk bringing up these topics in class. Religion and politics were also avoided, which are two culturally-charged topics inducing emotional bias. Raising these personal themes in the classroom is challenging for teachers since they must help students consider ideas that may be conflicting with students' own religious or political convictions. As put by Byford et al. (2009), controversy makes teachers and students ill at ease and puts friendly relationships in danger. Other studies have also shown that teachers try to avoid discussions of controversy because controversial issues concern disagreements of values (e.g., Hess, 2001; 2005).

Concerning the secondresearchquestion, exvolvement was made through routine, book-related topics. Since these types of topics can be dull and uninteresting by nature, the teachers used various interactive, multimodal strategies to surpass single sensory learning and create a more engaging classroom setting compared with the traditional didactic lectures. Therefore, auditory, visual and kinesthetic emotioncies were developed by the employment of pictures, powerpoints, videos, etc. to promote cognitive processing. Yet, in some cases, teachers preferred to merely touch the life-irrelevant or gender-based topics that would bore the students, by giving a brief oral description (auditory emotioncy). In fact, language learning classes and materials have the capacity for the consideration of different learning styles. The purpose of exvolvement is moving towards active learning, meaning to provide an environment that increases student performance while also motivating the students to learn and increasing classroom satisfaction (Miller et al., 2013). Basically, for this category, it is the teaching method tailored to the students' needs and interests that engages or disengages them.

Regarding the third research question, the teachers involved the learners to the level of applection (application + reflection) and appropriation (Pishghadam \& Shayesteh, 2017) by using life-related, job-related, future-related, complicated and thought-provoking 
topics. They believed that these everyday life topics, being associated with the students' previous knowledge and experiences conveyed from their L1, motivated the students more. The topics would actually address the natural curiosity of the students, to the degree that they would interestingly involve in and pursue even outside the class. The current findings are in line with Borsipour's (2016) study, in which EFL learners were interviewed to name three topics as the most desirable ones to be read in English class. Almost all of them chose the topics that to some extent represented their own job or major. In other words, the topics in which they were involved; they had either experienced or done research on them. The findings are also in agreement with the tenets of the humanistic approach in education, in which learners' motivation increases when the subject matter is of personal interest and relevance to the student (Williams $\&$ Burden, 1997). As a matter of fact, learners of English can take advantage of language classes by internalising skills necessary for life through a "life syllabus" (see Pishghadam, 2011). This means that learners not only learn linguistic and lexical issues but more importantly, life issues in order to improve their quality of life. Indeed, this is the ultimate goal of learning.

\section{CONCLUDING REMARKS}

Research (e.g., Bean, 1996) indicates that engaging students in the process of learning is of paramount importance. Prompted by active learning, the current study moved a step forward, distinguishing between avolvement, exvolvement and involvement. The role of teachers, as the heart of any educational system, was accordingly redefined to embrace this multidimensional envolvement. This new envolving role introduced to teachers brackets the art and science of teaching and can be seen as a prelude to initiate other studies. Given that qualitative analysis was employed to generate ideas and open up new horizons for researchers to conduct further studies, complementary empirical evidence needs to corroborate the efficacy of the new teacher's role in class. Moreover, in this study, the definition of envolver revolved only around topics discussed in class. The mentioned topics were broadly influenced by the Islamic culture of Iran. Some topics like sex and drinking may not be treated similarly in other cultures. Additionally, further studies need to be carried out to focus on other classroom aspects and practices rather than discussions. Studies can equally be done from the perspective of students to see how they define the role of envolver for teachers. Also, the concept of "students as envolvees", as a novel and different role for students, seems a researchworthy topic which requires further investigations. Since the major objective of the study was to broach the concept of "teacher as envolver" as a new role for teachers, the emphasis was merely placed upon teachers' views to scrutinize the topics they may avolve, exvolve or involve the learners in for more effective teaching. Yet, to have a more comprehensive picture of the relationship between envolver and envolvee in class, future studies can focus on the likely match between the topics teachers try to envolve and the topics students may like to be envolved in. Last but not least, investigating the relationship between envolvement and other teacher variables, such as teacher success, self-efficacy, creativity, motivation, burnout, etc. and their effects on students' learning can open up new horizons in education.

\section{ACKNOWLEDGEMENT}

The authors wish to express their sincere gratitude to the anonymous reviewers for their insightful comments which greatly contributed to improving the quality of the article.

\section{REFERENCES}

Atkinson, D. (2010) Extended, embodied cognition and second language acquisition, Applied Linguistics, 31(5), pp: 599-622.

DOI: https://doi.org/10.1093/applin/amq009

Ausubel, D. (1968) Educational psychology: a cognitive view, New York: Holt, Rinehart \& Winston.

Ausubel, D., Novak, J. O. and Hanesian, H. (1978) Educational Psychology: A Cognitive View, New York: Werbel \& Peck.

Banville, S. (2005) Creating ESL/EFL lessons based on news and current events, The Internet TESL Journal, 11(9) [Online] Available from: http://iteslj.org/Techniques/Banville-News/ [Accessed: $14^{\text {th }}$ December 2016].

Bean, J. (1996) Engaging ideas: the professor's guide to integrating writing, critical thinking, and active learning in the classroom, San Francisco: Josey Bass Publishers.

Binder J. R. (2016) In defense of abstract conceptual representations, Psychonomic Bulletin \& Review, 23, pp: 1096-1108.

DOI: https://doi.org/10.3758/s13423-015-0909-1

Blake, B. and Pope, T. (2008) Developmental psychology: incorporating Piaget's and Vygotsky's theories in classrooms, Journal of Cross-Disciplinary Perspectives in Education, 1(1), pp: 59-67 [Online] Available from: https://pdfs.semanticscholar.org/6c7b/9a7b4988df15c68a14434a5f162bef984723.pdf [Accessed: $3^{\text {rd }}$ January 2017].

Bogdan, R. and Biklen, S. K. (1997) Qualitative research for education, Boston: Allyn \& Bacon.

Borsipour, B. (2016) Emotioncy and willingness to read: a case of Iranian EFL learners, Unpublished M. Sc. thesis, Mashhad, Iran: Ferdowsi University of Mashhad. 
Brown, C. (2006) Cognitive Psychology, London: Sage Publication.

Byford, J., Lennon, S. \& Russell III, W. S. (2009) Teaching controversial issues in the social studies: a research study of high school teachers, Clearing House, 82(4), pp:165-170.

DOI: https://doi.org/10.3200/tchs.82.4.165-170

Claman, S., MacIntyre, P., Finegan, K. H., Gregersen, T. and Talbot, K. (2014) Examining emotional intelligence within the context of positive psychology interventions, Studies in Second Language Learning and Teaching, 4(2), pp: 327-353.

DOI: https://doi.org/10.14746/ssllt.2014.4.2.8

Dörnyei, Z. (2007) Research methods in applied linguistics: quantitative, qualitative, and mixed methodologies, Oxford: Oxford University Press.

Ertmer, P. A. and Newby, T. J. (2013) Behaviorism, Cognitivism, Constructivism: Comparing Critical Features From An Instructional Design Perspective, Performance Improvement Quarterly, 26(2), pp: 43-71.

DOI: https://doi.org/10.1002/piq.21143

Evans, R. W., Avery, P. G. and Pederson, P. V. (2000) Taboo Topics: Cultural Restraint on Teaching Social Issues, The Clearing House, 73(5), pp: 295-302.

DOI: HTTPS://DOI.ORG/10.1080/00098650009600973

Fosnot, C. T. (1996) Constructivism: a psychological theory of learning, In Fosnot, C. T. (Ed.) Constructivism: theory, perspectives, and practice, pp: 8-33, New York: Teachers College Press.

DOI: https://doi.org/10.1177/001698629704100308

Goleman, D. (1995) Emotional Intelligence, New York: Bantam Books.

Greenspan, S. I. and Shanker, S. G. (2004) The first idea: how symbols, language and intelligence evolved from our primate ancestors to modern humans, Cambridge, Massachusetts: Da Capo Press.

DOI: https://doi.org/10.1093/brain/awh564

Greenspan, S. I. and Wieder, S. (1998) The child with special needs: encouraging intellectual and emotional growth, Reading, Massachusetts: Addison-Wesley.

Greenspan, S. I. (1992) Infancy and early childhood: the practice of clinical assessment and intervention with emotional and developmental challenges, Madison, Connecticut: International Universities Press.

Hess, D. (2005) How do teachers political views influence teaching about controversial issues? Social Education, 69(1), pp: 47-48 [Online] Available from:https:/go.galegroup.com/ ps/anonymous?id=GALE\%7CA128604238\&sid=googleScholar $\& v=2.1 \& i t=r \&$ linkaccess $=a b s \& i s s n=00377724 \& p=A-$ ONE\&sw $=w$ [Accessed: $4^{\text {th }}$ December 2016].
Hess, D. (2001) Teaching students to discuss controversial public issues, Bloomington: Indiana University Social Development Center, pp: 1-3 [Online] Available from: http://www. brianscollier.com/wp-content/uploads/2015/05/Teaching-Students-to-discuss-controversial-public-issues1.pdf [Accessed: $20^{\text {th }}$ December 2016].

Jones, L. (2007) The student-centered classroom, New York: Cambridge University Press.

Jones, M. G. and Brader-Araje, L. (2002) The impact of constructivism on education: Language, discourse, and meaning, American Communication Journal, 5(3), pp: 1-10 [Online] Available from: https://pdfs.semanticscholar.org/f674/ 80594ca2ab46e25777653a8cc4f05fbe3135.pdf [Accessed: $10^{\text {th }}$ November 2016].

Lakoff, G. and Johnson, M. (1999) Philosophy in The Flesh: The Embodied Mind and its Challenge to Western Thought, New York: Basic Books.

Merriam, S. B. (1998) Qualitative research and case study applications in education, San Francisco, California: Jossey-Bass Publishers.

Miller, C. J., McNear, J. and Metz, M. J. (2013) A comparison of traditional and engaging lecture methods in a large professional-level course, Advances in Physiology Education, 37(4), pp: 347-355 [Online] Available from: https:/www.physiology. org/doi/pdf/10.1152/advan.00050.2013 [Accessed: 10 th $^{\text {th }}$ November 2016].

DOI: https://doi.org/10.1152/advan.00050.2013

Mir, M. M. and Jain, S. (2016) Constructivism: a complete teaching and learning approach, International Journal of Scientific Research, 4(11), pp: 362-363. DOI: https://doi. $\operatorname{org} / 10.15373 / 22778179$

Motschnig-Pitrik, R. and Holzinger, A. (2002) Student-centered teaching meets new media: concept and case study, $E d$ ucational Technology and Society, 5(4), pp: 160-172 [Online] Available from: https://www.jstor.org/stable/pdf/jeductechsoci.5.4.160.pdf? seq $=1 \#$ page_scan_tab_contents [Accessed: $18^{\text {th }}$ January 2017].

Parsley, K. and Corcoran, C. A. (2003) The classroom teacher's role in preventing school failure, Kappa Delta Pi Record, 39(2), pp: 84-87.

DOI: https://doi.org/10.1080/00228958.2003.10518370

Patton, M. (2002) Qualitative research and evaluation methods ( $3^{\text {rd }}$ Ed.), Thousand Oaks, California: Sage Publication.

Piaget, J. (1962) The stages of intellectual development of the child, In Stephen, H. and McDermott, J. (Eds.) Childhood Psychopathology, pp: 157-166, New York: International Universities Press. 
Pishghadam, R., Adamson, B. and Shayesteh, S. (2013) Emotion-Based Language Instruction (EBLI) as a new perspective in bilingual education, Multilingual Education, 3(9), pp: 1-16.

DOI: https://doi.org/10.1186/2191-5059-3-9

Pishghadam, R. and Shayesteh, S. (2017) The consolidation of life issues and language teaching on the life-language model of emotioncy, Humanising Language Teaching, 19(1), pp: 1-14 [Online] Available from: http://old.hltmag.co.uk/feb17/mart03. htm [Accessed: 23 ${ }^{\text {rd }}$ March 2017].

Pishghadam, R., Baghaei, P. and Seyednozadi, Z. (2016) Introducing emotioncy as a potential source of test bias: a mixed Rasch modeling study, International Journal of Testing, 16(5), pp: $1-14$.

DOI: https://doi.org/10.1080/15305058.2016.1183208

Pishghadam, R., Jajarmi, H. and Shayesteh, S. (2016) Conceptualizing sensory relativism in light of emotioncy: a movement beyond linguistic relativism, International Journal of Society, Culture and Language, 4(2), pp: 11-21 [Online] Available from: http://www.ijscl.net/article_17611_7951a00e46628cd5568c77564feb51ad.pdf [Accessed: $27^{\text {th }}$ October 2016].

Pishghadam, R., Tabatabaeyan, M. S. and Navari, S. (2013) A critical and practical analysis of first language acquisition theories: the origin and development, Mashhad, Iran: Ferdowsi University of Mashhad Publications.

Pishghadam, R. (2011) Introducing applied ELT as a new approach in second/foreign language studies, Iranian EFL Journal, 7(2), pp: 8-14 [Online] Available from: https://profdoc.um.ac.ir/articles/a/1022198.pdf [Accessed: $23^{\text {rd }}$ February 2016].

Pishghadam, R. (2015) Emotioncy in language education: from exvolvement to involvement, In $2^{\text {nd }}$ Conference on Interdisciplinary Approaches on Language Teaching, Literature, and Translation Studies, Ferdowsi University of Mashhad, Mashhad, Iran, 6-7 October 2015.

DOI: https://doi.org/10.12973/iji.2017.10420a

Pishghadam, R. (2016) Emotioncy, extraversion, and anxiety in willingness to communicate in English, In $5^{\text {th }}$ International Conference on Language, Education, and Innovation, London, United Kingdom, 27-28 May 2016 [Online] Available from: https://pdfs.semanticscholar. org/b199/0ba06af21c593ba4d9ebcb50adae609a08bb.pdf [Accessed: 27 ${ }^{\text {th }}$ October 2016].

Rogers, C. and Freiberg, H. J. (1994) Freedom to learn (3 ${ }^{\text {rd }}$ Ed.), New York: Merrill.

Rogers, C. (1983) Freedom to learn in the eighties, Columbus, Ohio: Charles Merrill.

Rogers, C. (1969) Freedom to learn, Columbus, Ohio: Charles Merrill.
Rubin, H. J. and Rubin, I. S. (2006) Qualitative interviewing: the art of hearing data ( $2^{\text {nd }}$ Ed.), Thousand Oaks, California: Sage Publication.

DOI: https://doi.org/10.4135/9781452226651

Salovey, P. and Mayer, J. D. (1990) Emotional intelligence, Imagination, Cognition and personality, 9(3), pp: 185-211.

DOI: https://doi.org/10.2190/dugg-p24e-52wk-6cdg

Silverman, D. (2013) Doing qualitative research: a practice handbook ( ${ }^{\text {th }}$ Ed.) London: Sage Publication.

Skinner, B. F. (1974) About Behaviorism, New York: Vintage. Spivey, N. N. (1997) The constructivist metaphor, Boston: Academic Press.

Swain, M. (2013) The inseparability of cognition and emotion in second language learning, Language Teaching, 3, pp: 195207.

DOI: https://doi.org/10.1017/s0261444811000486

Tekin, M. (2011) Discussing the unspeakable: a study of the use of taboo topics in EFL speaking classes, Journal of Theory and Practice in Education, 7(1), pp: 79-110 [Online] Available from: http://eku.comu.edu.tr/index/7/1/mtekin.pdf [Accessed: $14^{\text {th }}$ September 2016] .

Tormey, R. (2005) The cost of values: questioning the application of the term in development education, Development Education Journal, 11(2), pp: 9-11 [Online] Available from: https://www.researchgate.net/publication/284647325_The cost_of_values_Questioning_the_application_of_the_term in development education [Accessed: $12^{\text {th }}$ August 2016].

Vygotsky, L. S. (1986) Thought and language, Cambridge, Massachusetts: MIT Press.

Vygotsky, L. S. (1978) Mind in society: the development of higher psychological processes, Cambridge, Massachusetts: Harvard University Press.

Whorf, B. (1956) Language, thought, and reality: selected writings of Benjamin Lee Whorf, Cambridge, Massachusetts: MIT Press.

DOI: https://doi.org/10.2307/411163

Williams, M. and Burden, R. L. (1997) Psychology for Language Teachers: A Social Constructivist Approach, Cambridge: Cambridge University Press.

Yu, C. C. (2005) Schutz on transcendence and the variety of life-world experience, In Endress, M., Psathas, G. and Nasu, H. (Eds.) Explorations of the life-world continuing dialogues with Alfred Schutz, pp: 267-280, Netherlands: Springer.

DOI: https://doi.org/10.1007/1-4020-3220-x 11 